\title{
Morphological and Craniometric Features of the Skull of African Savanna Hare (Lepus microtis) Found in North-Central Nigeria
}

\section{Fatima O. Oyelowo ${ }^{1}$, Ifukibot I. Usende ${ }^{1 *}$, Idris A. Azeez ${ }^{2}$ and Abdulsalam E. Aminu ${ }^{1}$}

\author{
1 *Department of Veterinary Anatomy, University of Abuja, Federal Capital Territory, \\ Nigeria \\ ${ }^{2}$ Department of Veterinary Anatomy, University of Jos, Plateau state, \\ Nigeria
}

With 6 figures \& one table $\quad$ Received August, accepted for publication September 2017

\section{Abstract}

African savanna hare (Lepus microtis) belonging to the family Leporidae, is a placental mammal with vast economic and scientific importance ranging from the major source of protein for the teaming population to models of laboratory and genetic studies as well as valued game reserve. The aim of this study was to investigate the morphology and craniometric featuresof the skull of African savanna hare found in North-central Nigeria in an attempt to provide basic anatomical data of this wild rodent. The African savanna hare used were sampled from Gwagwalada area council, Federal capital territory, Abuja, Nigeria. Morphological and craniometric measurements were conducted on six skulls. Results

showed a foramen on the nasal bone and a non-serrated lateral margin of the margo supraorbital process of the frontal bone. The maxilla was trabeculated while the temporal bone was spongy-like in appearance. The palatine appeared perforated in a $\mathrm{W}$-shape. For craniometric results, the skull weight was $13.4 \mathrm{~g}$ with the mandible and $9.5 \mathrm{~g}$ without the mandibles. While the dorsal and ventral skull length was $10.5 \pm 0.8$ and $7.3 \pm 0.9$, the dorsal and ventral skull width was $3.1 \pm 0.2$ and $4.0 \pm 0.2$ with a dorsal and ventral skull index of 29.52 and 54.79 respectively. The orbital and cranial capacities were $5.8 \pm 0.6$ and $11.2 \pm 0.4$, and this could aid the vision and intelligence of this rodent. Our findings have provided baseline information on the skull morphology 
and craniometrics of the African savannahare, which would be of benefit in understanding morphofunctional and paleontological studies withemphasis on adaptive features necessary for domestication of this rodent.

Keywords: Morphology, Morphometrics, Orbits, Peculiarities, Lepusmicrotis, Cranial and Facial.

\section{Introduction}

African Savanna Hare (Lepus microtis) belongs to the family Leporidae and order Lagomorpha (Krygeret al., 2004).They are placental mammals' varying in size from small to medium sized (Chapman and Flux, 1990; Mengoni, 2011). They are generally herbivorous and long eared and constitute the base of many predator-prey interactions (Chapman and Flux, 1990; Mengoni, 2011). They are fast runners and although they typically live solitarily, can shift hundreds of kilometres in response to environmental changes or in search of food (Kryger et al., 2004).

African Savanna hares have been reported to be of economic and scientific importance due to their role as a major food source of protein, a model of laboratory animals, valued game reserve and can provide scientific insight into entire trophic systems (Chapman and Flux, 2008).

J. Vet. Anat.
Also serve as a model for population genetics (Alves et al., 2008). Recently, they have been seen as the subject of numerous international translocation (Moores et al., 2012) and traditional medicine for curing nearly 11 different ailments including diarrhoea, stomach ache, burns and wound (Magige, 2015).

Moores and Brown (2013) emphasized the need for research by both professionals and amateur biologists on this rodent as its identification has posed problems. In Africa, different species of hares have been identified based on their morphological traits (Suchentrunk et al., 2006; Palacios et al., 2008) such as body size, ratio of width of mesopterygoid space to minimum length of the hard palate, teeth features and quantity of black coloration in the ear (Kingdon, 2013). Basically, the basis for its identification despite the conspecific report on their taxonomy and distribution globally (Petter 1959; Slimen et al., 2005; Slimen et al., 2008) is the obvious russet area on the nape of the neck and its more coloured and roughed fur (Moores et al., 2012) but no particular emphasis has been placed on the skull morphology; a good anatomical area of species identification and to the best of our knowledge is non-existent in the literature.

The aim of the present study, therefore, was to investigate the skull 
morphology and morphometry of the African savanna hare in an attempt to contribute to information in this emerging field of anatomical studies of this wild rodent.

\section{Materials and Methods}

Six (four males and two females) African Savanna hares were used for this study. They were livetrapped at Gwagwalada area council, Federal Capital Territory, Abuja, North central Nigeria. A veterinarian physically examined all the hare, and there was no osteological deformity. Ethical approval was obtained from Animal Care and Use Committee of the University of Abuja, Nigeria. Animals were transported in metal cages to the Department of Veterinary Anatomy, University of Abuja and immediately euthanized by lethal intraperitoneal injection of xylazine $(10 \mathrm{mg} / \mathrm{kg})$ and ketamine $(100 \mathrm{mg} / \mathrm{kg}$ ) (Usende et al., 2016) and thereafter the heads were collected by cutting at the atlantooccipital joint. The heads were then processed, and skulls were prepared using cold water maceration techniques described by Ekeolu et al., (2016) and Tahon et al., (2013) with some modification. Briefly, the heads were soaked in cold water with ammonium solution and sodium hydroxide overnight to remove grease and soften the connective tissues and muscular attachment on

the bones. The solution was changed daily for seven days. Extraneous tissues on the bones were picked using thumb forceps, after brushing the muscle fibers and connective tissues attached to the bones with sponges (Ekeolu et al., 2016). The bones were then washed in $0.5 \%$ sodium hypochlorite solution (bleach) for 24hours and removal of any remaining muscles and ligaments was done. The skulls were left in the above solution for two changes of 3 hours each and then left to dry in sunlight. Specimens were photographed using Olympus digital camera (FE-360). Digital venire calliper, ruler and thread were engaged in taking the linear measurement of the various parts of the skull bones and mandible to the nearest 0.01 centimeters. All parameters measured were as described by Sarma (2006) and Saber and Gummow (2014).

1. Skull length (SL): taken as the distance between the highest point of the parietals to the middle of the rostral margin of the incisive bone. This was taken at the dorsal and ventral views and recorded as dorsal skull length and ventral skull length respectively.

2. Skull width (SW): taken as the distance between the two zygomatic arches. This

Vol. 10, No. 2, (2017) 85 - 107 
was taken at the dorsal and ventral views and recorded as dorsal skull width and ventral skull width respectively.

3. Cranial length $(C L)$ : taken as the distance from the central point of the fronto-nasal suture to the middle point of the nuchal crest.

4. Cranial width (CW): taken as the maximum distance between the highest points of the parietal bones.

5. Facial length (FL): taken as the distance from the frontonasal suture to the centre of the incisive bone.

6. Facial width (FW): taken as the distance between the caudal extents of the orbital rims.

7. Mandibular length: taken as the distance between incisor and caudal border of the mandible

8. Mandibular height: taken as the distance between the highest point of the coronoid process to the base of the mandible

9. Skull weight with mandibles (SWM) and Skull weight without mandible (SWWM) was taken usingsensitive bench top scale (LP 502A, China; with sensitivity of 0.1 to $5 \mathrm{~kg}$ ).

10. Orbital capacity (OC): all foramina opening into the or- bital cavity were plugged with plasticine, and the cavity filled with rice grains to the orbital rim and then contents emptied into a measuring cylinder.

11. Cranial capacity (CC): similar to the orbital capacity, all foramina opening into the cranial cavity were plugged with plasticine, and the cavity was filled with rice grains and then content emptied into a measuring cylinder.

12. Orbital height $(\mathrm{OH})$ : taken as the perpendicular distance between the supraorbital and infra-orbital margins of the orbit.

13. Orbital width (OW): taken as the horizontal distance between the rostral and caudal margins of the orbital rim.

14. Foramen magnum width (FMW): taken as the maximum distance between the mid lateral (horizontal) boundaries of the foramen magnum.

15. Foramen magnum height $(\mathrm{FMH})$ : taken as the maximum distance between the mid vertical boundaries of the foramen magnum.

16. Length of margo supraorbital (LMS): taken as the distance between the rostral and caudal extent of the margo supraorbital for the frontal bone. 
17. Width of margo supraorbital (WMS): taken as the distance from most lateral to most medial of the margo supraorbital of the frontal bone. This was taken at three points: Rostral (RMS), Middle (MMS) and caudal (CMS).

18. For the skull, cranial, orbital and facial indices, the equation of Miller et al.(1964) was used and are given below:

a. Skull index $=$ skull width/skull length $\mathrm{X} 100$

b. Cranial index $=$ cranial width/cranial length $\times 100$

c. Orbital index $=$ orbital width/orbital length X100

d. Facial index = facial width/facial length $X 100$

e. Foramen magnum index = foramen magnum width/foramen magnum height $X 100$

\section{Statistical analysis}

All numerical data generated from the craniometric studies were analyzed using Graph Pad prism version 6.0 (GraphPad Software, Inc., La Jolla, CA, USA) and presented as mean \pm standard deviation.

\section{Results}

The skull consists of the cranial bones, facial bones and hyoid apparatus. The cranial and facial bones give boundaries to the cranial and

nasal cavities respectively. The bones are either paired or unpaired and thus described as follows:

\section{Os occipital (Occipital bone)}

The occipital makes up the boundary that completely encircles the foramen magnum (passage of spinal cord) at the most caudal part of the skull. The supra-occipital or squamous part of the occipital (Fig 1/1) forms the dorsal boundary; the flat basioccipital (Fig 1/3) forms the ventral boundary while the exoccipital (Fig 1/2) forms the lateral boundary. The supra-occipital is a flat butterflylike bone bearing a distinct nuchal crest (Figs 1/5, 2/20, 3/2) about its middle. It is fused with the interparietal (Fig 1/9) and paired parietal (Fig 1/10) rostrally forming both internal and external protuberances (Figs 1/6, 3/3). The external protuberance fuses with the nuchal crest.

The exoccipital flanks the foramen magnum on either side dorsally and ventrally, it bears two distinct occipital condyles (Fig 1/8) that articulate with the wings of the atlas. Lateral to these condyles are distinct jugular processes (Figs 1/7, 3/5). The hypoglossal fossa is located between each condyle and the jugular process bearing two hypoglossal canals (Fig3/6).

The basilar part (basioccipital) (Figs $1 / 3,3 / 10$ ) is slightly shallow and 
wide. If fuses with the laterals on either side and with the basisphenoid (Fig 3/11) rostrally.

\section{Os basisphenoidale \& Os Pre- Sphenoidale (Sphenoid bone)}

The unpaired sphenoid bone is medianly located and divided into two parts; the basisphenoid (Fig 3, 11) and presphenoid (Fig 3/14) which are separated by a distinct fissure.

Dorsally, the wide basisphenoid bears a slightly shallow longitudinal depression, which is continuous with the basioccipital. It also bears a cranio-pharyngeal canal (Fig 3/13) that opens into the hypophyseal fossa. Ventrally, it bears two distinct ridges that taper rostrally towards the presphenoid bone. The presphenoid is much narrower, triangular and thickened caudally. Both basi- and presphenoid bear alasphenoids and orbitosphenoid respectively, which are wing projection from the body that extends into the caudal border of the orbital wall. An orbital foramen is located between the two wings. The alasphenoid fuses with the frontal bone and pterygoidhamulus of the pterygoid bone. The orbitosphenoid is fused with the frontal bone dorsally, ethmoid cranially and palatine ventrally. The ethmoid foramen (Fig 4/27) is situated at the frontosphenoid suture.

\section{Os parietale (Parietal bone)}

J. Vet. Anat.
These are paired flat bones (Figs $1 / 10,2 / 3,4 / 18$ ) that make up the dorsal boundary of the cranial cavity and unite at the midline by the interparietal suture. Slightly convex in shape, it forms a fusion with the frontals and squamous part of temporal laterally on either side. Caudally it fuses with the interparietal and occipital bones.

\section{Os interparietale (Interparietal bone)}

These are two tiny oval plates (Figs $1 / 9,2 / 18,4 / 20$ ) situated between the parietals, squamous and lateral parts of the occipital bones. It is slightly spongy in nature.

\section{Os frontale (Frontal bone)}

The frontal bone (Figs $1 / 13,2 / 2$,) is made up of narrow, long pair of bones making up part of the dorsal wall of the cranial cavity. It fuses with the parietals caudally. It is made up of two parts: the slightly convex horizontal plate and a vertical plate. The margo supraorbital (Figs $1 / 14,2 / 7,3 / 20,4 / 14$ ) located on the lateral margin of the horizontal plate extends rostrally and caudally over the orbit forming the rostral (Fig 2/10, 4/15) and caudal (Figs $2 / 11,4 / 16$ ) supraorbital incisures and processes respectively against the frontal bone. The caudal incisura is twice the length of the rostral one. Rostrally, the nasal processes 
(Fig 4/17) of the frontal bone fuse with the paired nasal bones (Figs $2 / 1,4 / 1)$. The shape of the nasal processes of either side ends at an angle forming an isosceles triangular shape. Furthermore, the frontal bone bears a thin lateral process.

\section{Orbita (Orbits)}

These are incomplete circular bony structures located on either side of the skull about its middle. It consists of frontal on its dorsal boundary, ethmoid as its rostromedial surface, alasphenoid and orbitosphenoid forming the mediocaudal surface. The temporal (Figs1/15, 4/19) forms the caudal surface, while the zygomatic arch (Fig 4/35) makes up the lateral boundary. The lacrimal (Fig 4/13) forms the proximal rostral boundary while the maxillary tuber (Fig 4/8) forms the distal rostral boundary.

A pterygopalatine fossa is present between the orbital median surface and the maxillary tuber. This fossa bears three foramina namely: the most proximal maxillary foramen which leads to the infraorbital canal, the sphenopalatine foramen that leads to the nasal cavity and the caudal palatine that leads into the palatine canal

The two orbits are separated by a thin median bony septum. The rostral part of the bony septum bears a

large optic foramen (Fig 4/28) through which the two orbits communicate.

\section{Os lacrmale (Lacrimal bone)}

These form the rostral boundary of the orbit on its proximal end. These are paired small, thin bones bearing a nasolacrimal foramen (Fig 4/12) that leads into the nasolacrimal canal for passage of lacrimal duct from the gland. Above the foramen is the laterally situated lacrimal hamulus.

\section{Os temporale (Temporal bone)}

This is a paired bone located between the parietal dorsally, rostrally with frontal and sphenoid ventrally. It has four parts: the squama, mastoid, tympanic and petrous. The squama is bordered by the squamous occipital dorsocaudally and the other 3 parts. The squama is irregular in shape, contributing most to the lateral wall of the cranial cavity. Rostrally it gives out a zygomatic process (Fig4/31) forming the lateral wall of the orbit. The ventral part of this process bears a mandibular fossa to which the condyle of the mandible articulates. A small tubercle projects above the zygomatic process.

Ventral to the squama is the mastoid part (Fig 4/30) that is spongylike in appearance. It is attached to 
the occipital caudally and tympanic part of temporal distally. Ventral part of the temporal bone bears the bulbous tympanic bulla (Figs $3 / 7$, $4 / 25$ ) that gives exit to the external acoustic meatus (Figs1/11, 2/15, $4 / 24$ ), which is a short tube-like structure. The retrotympanic process (Fig 4/22) is located dorsocaudally to the base of the external acoustic meatus. Ventral to this is the styloid process. The petrosal part is behind the mastoid part, and the small jugular process is located about the middle and ventral border of the bulla respectively. The large prominent carotid canal is situated at the ventromedial part of the bulla towards the basisphenoid.

\section{Os ethmoidale (Ethmoid bone)}

This bone forms the rostral and caudal boundaries of the cranial and nasal cavities respectively. It bears a sieve-like cribriform plate and a perpendicular plate. The olfactory nerves emanating from olfactory bulb of the brain pass through the cribriform plate, while the bony nasal crest makes up the perpendicular plate. A narrow crista galli divides the cribriform plate into 2 parts. The plate also bears scattered large foramina. The perpendicular plate forms the caudal nasal septum in conjunction with the vomer bone (Fig 3/15).

\section{Turbinate bones}

These are scroll-like bony plate projections in the nasal passage from the cribriform plate of ethmoid that projects rostrally.

\section{Os nasale (Nasal bone)}

These are paired bones located rostrally to the frontals and elongated rostrally. Each nasal bone is fused with the frontal caudally and the nasal process of the incisive (Figs $2 / 4$, $4 / 3$ throughout its length laterally. Dorsally the bone is smooth horizontally and tapers or decline ventrally midway of its length. About $2 / 3$ the length, it bears a nasoincisive notch which is slightly convex lateroventrally. This notch bears a foramen (Fig4/29). Rostrally, the nasals end as a curved shape to conform to the nasal openings. The openings are divided into two halves by a median cartilaginous nasal septum that extends caudally to meet the ethmoid bone.

\section{Os incisivum (Incisive bone)}

The incisive bones (Figs 3/28, 4/2) are paired bones that make up the most rostral aspect of the skull. It presents a body, two surfaces and three processes. The palatine surface is slightly concave while the labial surface is slightly convex. The nasal process (Fig 4/3) is long, thin and does not fuse with the nasal and maxillary bones (Fig 4/4). How- 
ever, it makes up part of nasal cavity lateral wall. The palatine process (Fig $3 / 28$ ) is very much thinner and fuses with the other rostrally only, close to the incisor teeth and further fuse again towards the first premolar. The alveolar process (Fig 3/32) is very short. Each alveoli process bears alveolar sockets for four incisor teeth with 2 being most rostral.

\section{Maxilla}

The upper jaw is mainly made up of the paired maxilla (Fig 4/4). The body bears two surfaces, which present a trabeculae-like appearance made up of numerous foramina lateromedially. The infraorbital foramen (Fig 4/7) is situated amongst the foramina at the base of the zygomatic arch. Immediately behind the foramen is the zygomatic process (Fig 4/9) of the maxilla, which bears a prominent facial crest. The medial surface is concave dorsoventrally forming part of the nasal cavity wall. The thin dorsal border fuses with the nasal process of incisive and lateral process of frontal bones while the thick, strong ventral border is somewhat straight and smooth. The latter extends caudally and widens mediolaterally as the alveolar process (Fig 4/33) to accommodate the alveolar canals for the two premolar and four molar teeth.
A narrow bony palatine process of the maxilla (Fig 3/26) is situated rostrally to the horizontal plate of the palatine (Fig 3/18). Both the maxilla and palatine fuses together to form part of the hard palate.

The maxilla extends caudally towards the orbit to form a medial maxillary tuber (Fig 4/8) and a lateral facial tuber (Fig 4/6). The maxillary tuber is thick and wide rostrocaudally as it presents a pterygopalatine fossa against the orbital median surface.

The facial tuber is very small, fuses with the temporal process of zygomatic (Fig 1/12) bone to form the zygomatic arch alongside the zygomatic process of temporal bone (Fig 4/31).

\section{Os zygomaticum (Zygomatic bone)}

The zygomatic bones (Fig 4/11) are two small bones that make up part of the lateral boundary of the orbit. It has two surfaces, the flat orbital and concave malaris surfaces. It fuses with the maxilla by its zygomatic process rostrally and the zygomatic process of the temporal bone caudally. The suture line between the bones is fused. The temporal process of the zygomatic bone runs caudally towards the zygomatic process of temporal bone. The temporal process has a projection (Fig 
4/32) caudally at the end of the zygomatic arch.

\section{Os palatinum (Palatine bone)}

The paired palatine has both perpendicular part (Fig 3/17) and horizontal part (Fig 3/18). The horizontal part forms the caudal hard palate at which the soft palate attaches. It also bears the major palatine foramen (Fig 3/27), which is rostrad and minor palatine foramen. The perpendicular partin conjunction with basisphenoid and pterygoid process makes up the dorsal and lateral walls of the nasopharyngeal meatus, choanae (Fig 3/19) and nasal cavity opening into the nasophar$y n x$. The rostral part of this plate overlaps the alveolar process of the maxillae. The caudal part forms 2 lateral processes of which the external process overlaps the pterygoidhamulus, and the internal process overlaps the pterygoid process of sphenoid bone.

\section{Os pteygoideum (Pterygoid bone)}

These are paired, tiny bony plates between the palatine rostrally and the sphenoid caudally. It is made up of the squamous part and pterygoid hamulus. The squamous part is convex and makes up part of the lateral and ventral walls of the cranial cavity. It is located caudally and fuses with the tympanic bulla of the temporal bone. It also fuses with the pterygoid process of sphenoid bone. It forms the Pterygoid hamulus, which is a thin hook-shaped process on its free margin. This makes up pterygoid fossa between the two laminae of the bone.

\section{Vomer}

This is a thin single bony plate that makes up the ventral part of the nasal septum. It is a bent arch, located rostrally at the palatine process sulcus and caudally at the rostral margin of presphenoid bone.

\section{Mandibula (Mandible)}

This makes up the lower jaw (Fig 5). It consists of two halves, each made up of a body (Figs 5/1, 5/2) and a vertical ramus (Fig 5/3). The thick body can be subdivided into rostral and caudal parts. The rostral incisive part (Fig 5/1) is convex on its labial surface (Fig 5/7) and concave on its lingual surface. The most rostral part bears alveolar sockets for the incisor pair of teeth. The molar caudal part bears sockets on its dorsal border to accommodate the roots of the five cheek teeth (Fig $5 / 18$ ) and a small oval mandibular foramen.

The molar part (Fig 5/2) bears a mandibular foramen on its lingual surface, which is continuous cranially toward the incisive part and exit as the mental foramen (Fig 5/13), 
which is made up of two openings. Pitted small numerous foramina (Fig $5 / 10$ ), which are numerous and also seen in this region.

The thin, flat, vertical ramus bears masseteric (Fig 5/4) and pterygoid fossae on the lateral and medial surfaces respectively. Caudal to the body and ventral to the ramus is the rounded angle of the mandible (Fig $5 / 15)$. Proximal to this is the angular process (Fig 5/16), which bears a sharp pointed edge. Proximal to the angular process is a wider edge called the condyloid process (Fig 5/9) where the TMJs are situated. Mandibular notch (Fig 5/6) separates the condyloid process from a rostral smaller coronoid process (Fig $5 / 5)$.

\section{Morphometrics}

Some of the morphometric parameters taken are represented in figure 6 and the results of the morphometric measurements are presented in table 1. The dorsal skull length was $10.5 \pm 0.8$ while the ventral was $7.3 \pm 0.9$. The dorsal width of the skull was $3.1 \pm 0.2$ whereas the ventral was $4.0 \pm 0.2$. On the other hand, the cranial length and width were $7.1 \pm 0.4$ and $3.5 \pm 0.1$ respectively while the facial length and width were $3.3 \pm 0.2$ and $3.2 \pm 0.1$ respectively. Orbital height and width were $3.4 \pm 0.3$ and $2.8 \pm 0.3$ respectively.

\section{Discussion}

We report that the skull of African savanna hare (Lepus microtis) consists of the cranial bones, facial bones and hyoid apparatus. Similar findings have been documented for the domestic rabbit (Oryctolagus cuniculus) (Farag et al., 2012).

Concerning the occipital bone of the African savannah hare, four parts were observed in this study; supraoccipital, basioccipital and two exoccipital similar to reports of Farag et al., (2012) and Crabb (1931) in domestic rabbit. Again we reported a notched foramen magnum corroborating the work of Farag et al., (2012). The supraoccipital is a flat butterfly-like bone. However, the condyles and jugular process are typical of other mammals (Shawulu et al., 2011).

For the basisphenoid, we observed a perforated rostrophargngeal canal that opens into the hypophyseal fossa (Sisson and Grossman 1975, Shawulu et al., 2011). This observation is consistent with that of domestic rabbit Farag et al., (2012). However, while the canal was centrally located in the domestic rabbit, we observed a lateral located canal in the African savannah hare. The hypophyseal fossa accommodates the hypophyseal gland (Sisson and Grossman 1975; Shawulu et al., 2011). 
Our observations on the parietal bone simulate the report of Farag et al., (2012) in domestic rabbit and lack the zygomatic process. Earlier, Shawulu et al. (2011) suggested that prominence of the interparietal suture could predispose to fracture. This is a possibility in the African savanna hare. The parietal bone also bears a smooth external surface, which is in line with the findings of Cabon-Raczynska, (1964). The interparietal bone on the other hand composed of slightly spongy two bony plates. This simulates the findings of Cabon-Raczynska, (1964) in the European hare as being porous in structure.

On the frontal bone, we observed a non-serrated margin of the margo supraorbital process in African savanna hare skull. Although Farag et al., (2012) observed this feature in domestic rabbit, to be serrated. In addition, the caudal incisura is twice the length of the rostral one. Our observation on museum specimen of the skull of other domestic mammals used during Veterinary anatomy practical showed the absence of this incisura.

The orbits of African savanna hare are similar to that described by Farag et al., (2012) for the domestic rabbit. The thin median bony sep- tum observed that separate the two orbits could be a point of fracture in this species.

The mastoid part of the temporal bone presents spongy-like appearance at the ventrolateral part, which also forms the part of the cranial cavity. This has not been reported in domestic mammals. A large prominent carotid canal was also observed on the temporal bone of the skull of African savanna hare that simulates the work of Farag et al., (2012) for the domestic rabbit.

Our study of the nasal bone showed a foramen on the naso-incisive notch. This foramen has not been reported in domestic and wild animals. We venture to call it nasal foramen (of Oyelowo and Usende).

It was observed in this study that the nasal process of incisive bone does not fuse with the nasal and maxillary bones as in other domestic species. The zygomatic bone was also observed to have a flat orbital and concave malaris surfaces. Although it simulates the study of Cabon-Raczynska, (1964), this is different from other domestic species.

Morphometric data are useful for the theoretical importance of functional 
morphology as well as either absolute or relative size of particular interest (Saber and Gummow 2014), and we present for the first time, data on the morphometrics of the African savanna hares. In our report, the dorsal and ventral skull index of the African savanna hare were 29.52 and 53.79 respectively. Saber and Gummow (2014) showed the skull index of koala, wombat and wallaby to be $48.78,111.21$ and 74.75 respectively. Although their study only looked at the dorsal skull index, comparing their report with our present report of 29.52 for dorsal skull index, this was relatively lower compared to the report of Saber and Gummow (2014). Similarly, we reported a facial index of 96.97 for the African savanna hare while Saber and Gummow (2014) reported 186.11, 175.24 and 114.29 for koala, wombat and wallaby respectively.

Concerning the cranial capacity, Saber and Gummow (2014) reported $20.0 \pm 2.4,61.7 \pm 11.8$ and $33.5 \pm 37$ for koala, wombat and wallaby respectively. Earlier, Sarma (2006) showed the cranial capacity of akagani goat to be 113 while Yahaya et al, (2012) reported $487.92 \pm 7.55$ for one hump camel. Interestingly, Hajnis (1962) stated that skull capacity is in no way dependent on the form of the skull. However, in koala, about $40 \%$ of the cranium is filled with cerebrospinal fluid (Saber and Gummow, 2014). In the Wombat, the cranial index has been reported to be 50. 961 (Saber and Gummow, 2014). This is higher than the 46.67 reported in our work for African savanna hare.

Brain capacity/size in relationship to intelligence in school children (Estabrooks, 1928) and animals (Hicks and Dougherty, 2013) have been studied and in wombats and wallabies could reflect their intelligence for getting food and water, managing territory, offences and in defence (Saber and Gummow, 2014).

Our findings have provided baseline information on the skull morphology and morphometrics of the African savanna hare, which would be of benefit in understanding morphofunctional and paleontological studies with an emphasis on adaptive features necessary for domestication of this rodent.

\section{References}

Alves PC, Melo-Ferreira J, Freitas $H$, Boursot $P$ (2008): The ubiquitous mountain hare mitochondria: multiple introgressive hybridization in hares, genus Lepus. Philosophical transactions of the Royal Society of London. Series B, Biological sciences, 363: 2831-2839. 
Cabon-Raczynska K (1964): Studies on the European Hare. III. Morphological variation of the skull. Actatheriologica 9(17): 249-285

Chapman JA, Flux JEC (1990): Rabbits, Hares and Pikas. Status Survey and Conservation Action Plan. IUCN/SSC Lagomorph Specialist Group, Gland, Switzerland.

Chapman JA, Flux JEC (2008): Introduction to the Lagomorpha. In Lagomorph Biology. Springer Berlin Heidelberg, Germany. Pg. 1-9.

Crabb, E.D. (1931): Principles of functional anatomy of the rabbit. $P$. Blackstone's son \& co., Inc., 1931.

\section{Ekeolu OK, Usende IL, Adejumobi} OA, Azeez Al, Orolu-Adedeji MO. (2016): Comparative morphometric study of the right and left pectoral and pelvic bones of cattle egret (Bubulcus ibis). Inter J Vet Sci, 5(4): 285-289.

Estabrooks GH (1928): The relationship between cranial capacity, relative cranial capacity and intelligence in school children. Journal of Applied Psychology, 12(5): 524-529

Farag FM, Daghash SM, Mohamed EF, Hussein MM, and Hagrass SM (2012): Anatomical studies on the skull of the domestic rabbit (Oryctolaguscuniculus) with spe- cial reference to the hyoid apparatus. J. Vet Anat. 5(2):49-70

Hajnis K. (1962): Evaluation of different methods of calculation of skull capacity for lineal measurements. Ceskolov. Merfol., 10: 220233

Hicks K, Dougherty M. (2013): Finding the intelligence of an animal. Field study presented to STEM Teacher Academy, Rider University. http://riderstem.weebly.com/cranialvolume-intelligence.html

Kingdon J. (2013): Mammalian evolution in Africa. In: Kingdon JS, Happold D, Hoffmann M et al (Eds.), The Mammals of Africa, Introductory chapters and Afrotheria, Bloomsbury, Amsterdam, 1:75-100

Kryger U, Robinson TJ, Bloomer $P$ (2004): Population structure and history of southern African scrub hares, Lepussaxatilis. Journal of Zoology, 263: 121-133.

Magige FJ. (2015): Traditional medicinal uses of small mammal products: a case study of the African savannah hares, crested porcupines and rock hyraxes in Serengeti District, Tanzania.Tanzania Journal of Science. 14(1): 64-71

Mengoni C. (2011): Phylogeny and genetic diversity of Italian species of 
hares (genus Lepus) PhD thesis. Università di Bologna, Bologna.

Moores R, Brown D. (2013): African Savannah Hare Lepusmicrotisnear Tantan - a new mammal species for North Moroccan Atlantic Sahara.Go-South Bulletin, 10: 263265

Moores, R, Brown D, Martin R, Lees AC. (2012): Status and identification of hares Lepus sp. in Western Sahara and Southern Morocco Go-South Bulletin 9: 126-130.

Palacios, F.; Angelone, C.; Alonso, G.; Reig, S. (2008): Morphological evidence of species differentiation within Lepuscapensis Linnaeus, 1758 (Leporidae, Lagomorpha) in Cape Province, South Africa. Mammalian Biology - Zeitschrift für Säugetierkunde, (73): 358-370.

Petter, F. (1959): Eléments d'unerévision des lièvresafricains du sous-genre Lepus. Mammalia (23): 41-67.

Saber, A.S. and Gummow, B. (2014): Morphometric studies on the skull in three marsupial species (Koala, Wombat, Wallaby). J. vet. Anat. 7(2):117-131

Sarma, K. (2006): morphological and craniometrical studies on the skull of kagani goat (caprahircus) of
Jammu region. Int. J. Morphol 24(3):449-455

Shawulu, J.C.; Kwari, H.D.; Olopade, J.O. (2011): Morphology of the Bones of the Skull in the Sahel Ecotypes of Goats(Capra hircus)in Nigeria. J. Vet. Anat. 4(2): 1 - 13

Sisson S, Grossman JD. (1975): The Anatomy of the Domestic Animals. Vol.2, 5th ed. W. B .Saunders Company, Philadelphia.

Slimen, HB, Suchentrunk F, Memmi A, Ben Ammar Elgaaied A. (2005): Biochemical genetic relationships among Tunisian Hares (Lepusspecies), South African Cape Hares (L. capensis), and European Hares (L. europaeus). Biochemical Genetics.43: 11-12.

Slimen HB, Suchentrunk F, Stamatis C, Mamuris Z, Sert $H$, Alves PC, Kryger U, Shahin AB, Elgaaied ABA. (2008): Population genetics of cape and brown hares (Lepuscapensis and L. europaeus): A test of Petter's hypothesis of conspecificity.Biochemical Systematics and Ecology 36(1): 22-39

Suchentrunk $F$, Slimen HB, Stamatis C, Sert H, Scandura M, Apollonio M, Mamuris Z. (2006): Molecular approaches revealing prehistoric, historic, or recent translocations and introductions of hares 
(genus Lepus) by humans. Hum Evolution 21:151-165

Tahon RR, Ragab SA, Abdel Hamid MA, Rezk HM. (2013): Some anatomical studies on the skeleton of chicken, A PhD thesis. Anatomy and Embryology, Faculty of veterinary medicine, Cairo University

Usende IL, Leitner DF, Neely E, Connor JR, Olopade JO. (2016):

\section{Corresponding author}

Dr.Usende, Ifukibot Levi

Department of Veterinary Anatomy,

University of Abuja, FCT

Nigeria.

Email: ifukibot.usende@uniabuja.edu.ng
The Deterioration Seen in Myelin RelatedMorpho-physiology in Vanadiumexposed Rats is Partially Protected byConcurrent Iron Deficiency. NigeriaJournal of Physiological Sciences,31(1): 11-22.

Yahaya A, Olopade JO, Kwari D, Wiam IM. (2012): Osteometryof the skull of one-humpedcamels. Part I: immature animals. IJAE, 117: 2333. 
Table (1): Mean \pm SD of skull parameters of African savanna hare (Lepus microtis) found in North central Nigeria

\begin{tabular}{|c|c|c|}
\hline SN & Parameter & Mean \pm SD \\
\hline 1 & Skull weight with mandibles (g) & 13.4 \\
\hline 2 & Skull weight without mandibles $(\mathrm{g})$ & 9.5 \\
\hline 3 & Dorsal skull length & $10.5 \pm 0.8$ \\
\hline 4 & Ventral skull length & $7.3 \pm 0.9$ \\
\hline 5 & Dorsal skull width & $3.1 \pm 0.2$ \\
\hline 6 & Ventral skull width & $4.0 \pm 0.2$ \\
\hline 7 & Dorsal skull index & 29.52 \\
\hline 8 & Ventral skull index & 54.79 \\
\hline 9 & Cranial length & $7.1 \pm 0.4$ \\
\hline 10 & Cranial width & $3.5 \pm 0.1$ \\
\hline 11 & Cranial index & 46.67 \\
\hline 12 & Cranial capacity & $11.2 \pm 04$ \\
\hline 13 & Facial length & $3.3 \pm 0.2$ \\
\hline 14 & Facial width & $3.2 \pm 0.1$ \\
\hline 15 & Facial index & 96.97 \\
\hline 16 & Orbital height & $3.4 \pm 0.3$ \\
\hline 17 & Orbital width & $2.8 \pm 0.3$ \\
\hline 18 & Orbital index & 82.35 \\
\hline 19 & Orbital capacity & $5.8 \pm 0.6$ \\
\hline 20 & Length of margo supraorbital & $1.9 \pm 0.2$ \\
\hline 21 & Rostral distance between margo supraorbital & $2.2 \pm 0.4$ \\
\hline 22 & Mid distance between margo supraorbital & $2.5 \pm 0.3$ \\
\hline 23 & Caudal distance between margo supraorbital & $3.0 \pm 0.7$ \\
\hline 24 & Foramen magnum height & $1.8 \pm 0.1$ \\
\hline 25 & Foramen magnum width & $1.9 \pm 0.3$ \\
\hline 26 & Foramen magnum index & 105.5 \\
\hline 27 & Mandibular length & $6.0 \pm 0.9$ \\
\hline 28 & Mandibular height & $3.2 \pm 0.7$ \\
\hline
\end{tabular}




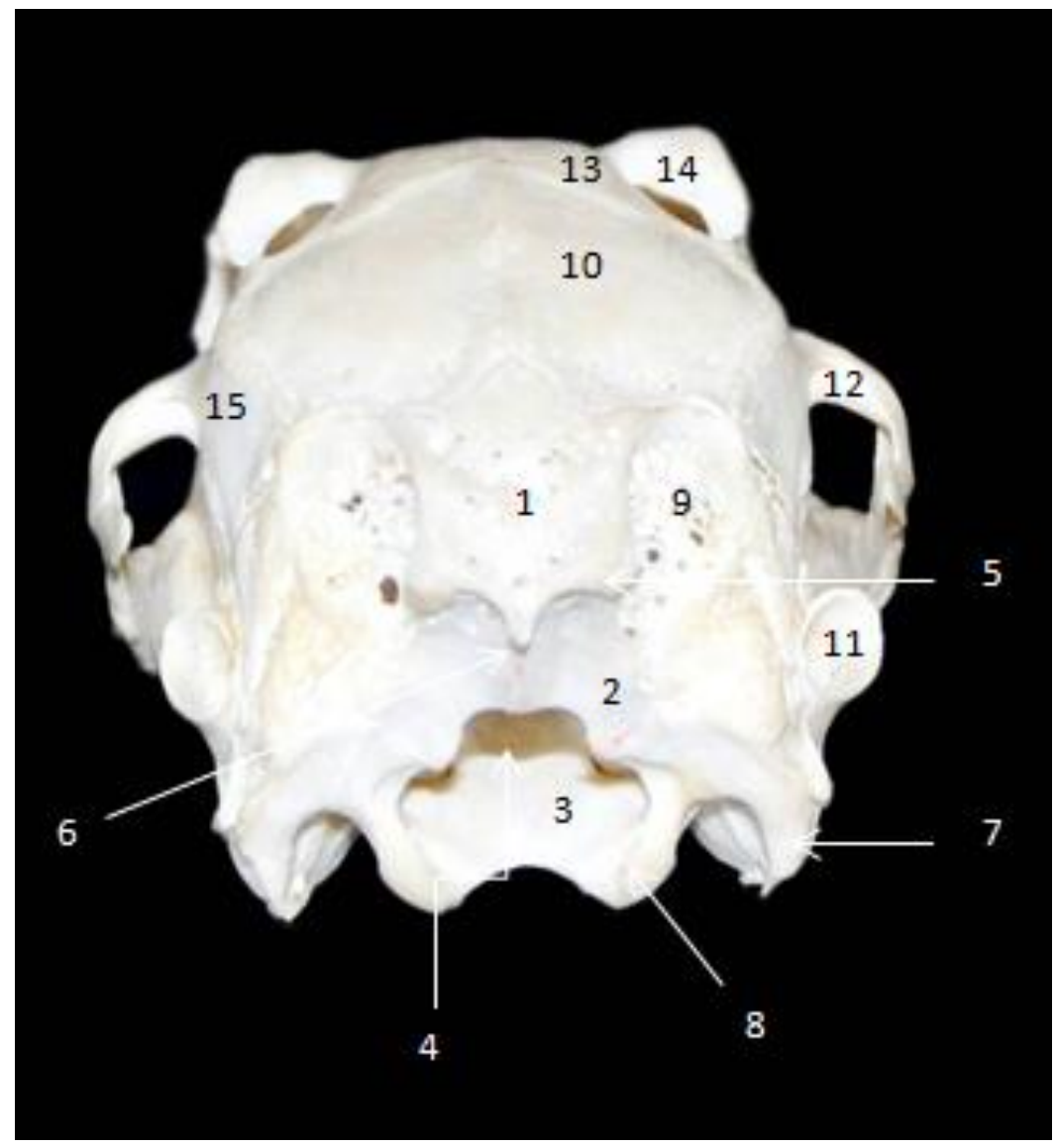

Fig (1): Dorsocaudal view of the skull of African Savanna Hare

1 Squamous part of occipital bone, 2 Exoccipital of occipital bone, 3 Exoccipital of occipital bone, 4 Basilar part of occipital bone, 5 Foramen magnum, 6 Nuchal crest, 7 External occipital protuberance, 8 Jugular process, 9 Occipital condyle, 10 Inter-parietal bone, 11 Parietal bone, 12 External acoustic meatus, 13 Temporal process of zygomatic bone, 14 Frontal bone, 15 Supraorbital process, 


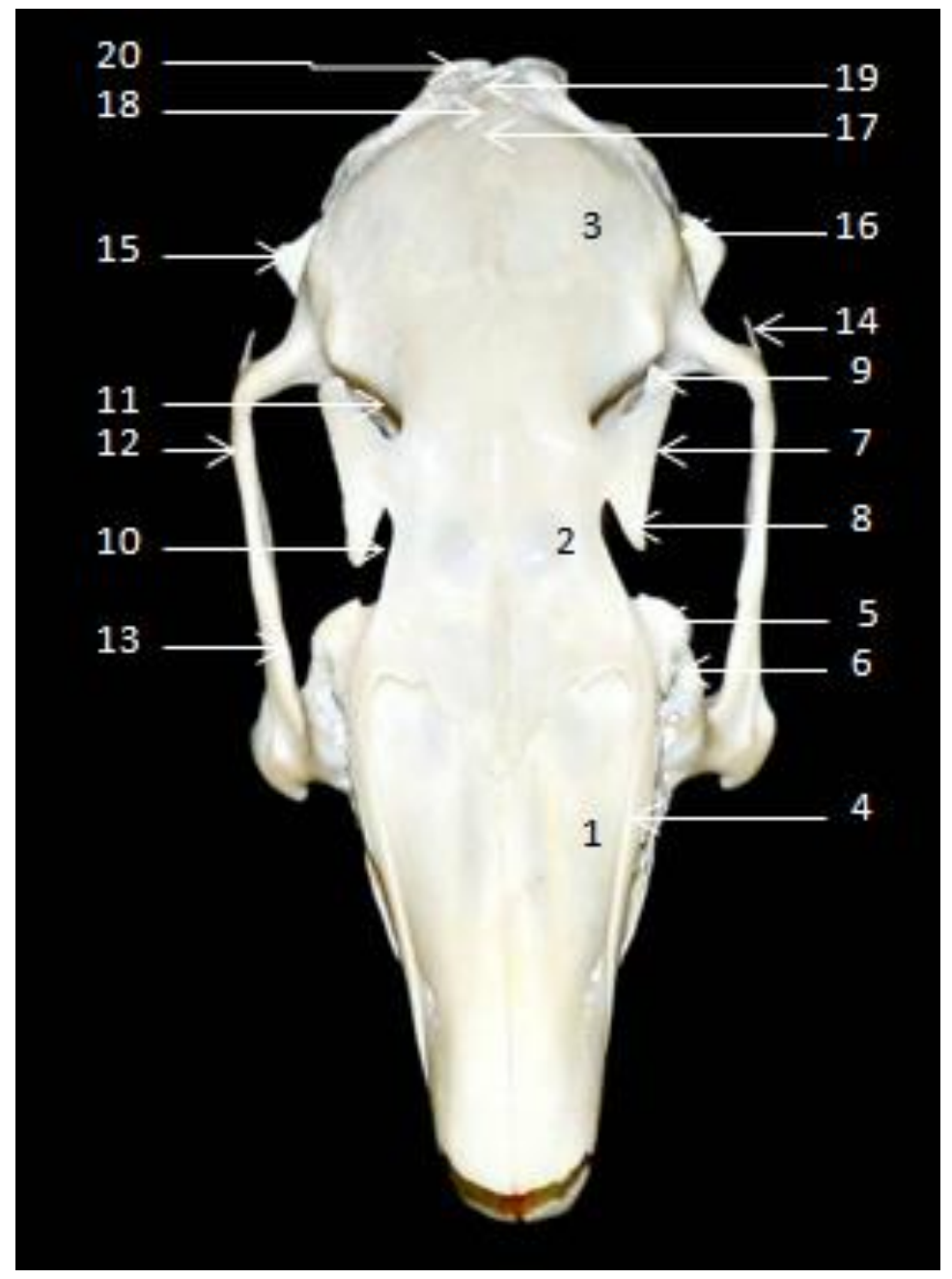

Fig (2): Dorsal view of the skull of African Savanna Hare

1 Nasal bone, 2 Frontal bone, 3 Parietal bone, 4 Nasal process of incisive bone, 5 Lacrimal bone, 6 Facial tuber, 7 Supraorbital margin, 8 Rostral branch of 7, 9 Caudal branch of 7, 10 Rostral supraorbital incisures, 11 Caudal supraorbital incisures, $12 \mathrm{Zy}$ gomatic process of maxilla bone, 13 Zygomatic process of temporal bone, 14 Zygomatic bone, 15 External acoustic meatus, 16 Squamous part of temporal bone, 17 External sagittal crest, 18 Interparietal bone, 19 Squamous part of occipital bone, 20 Nuchal crest 


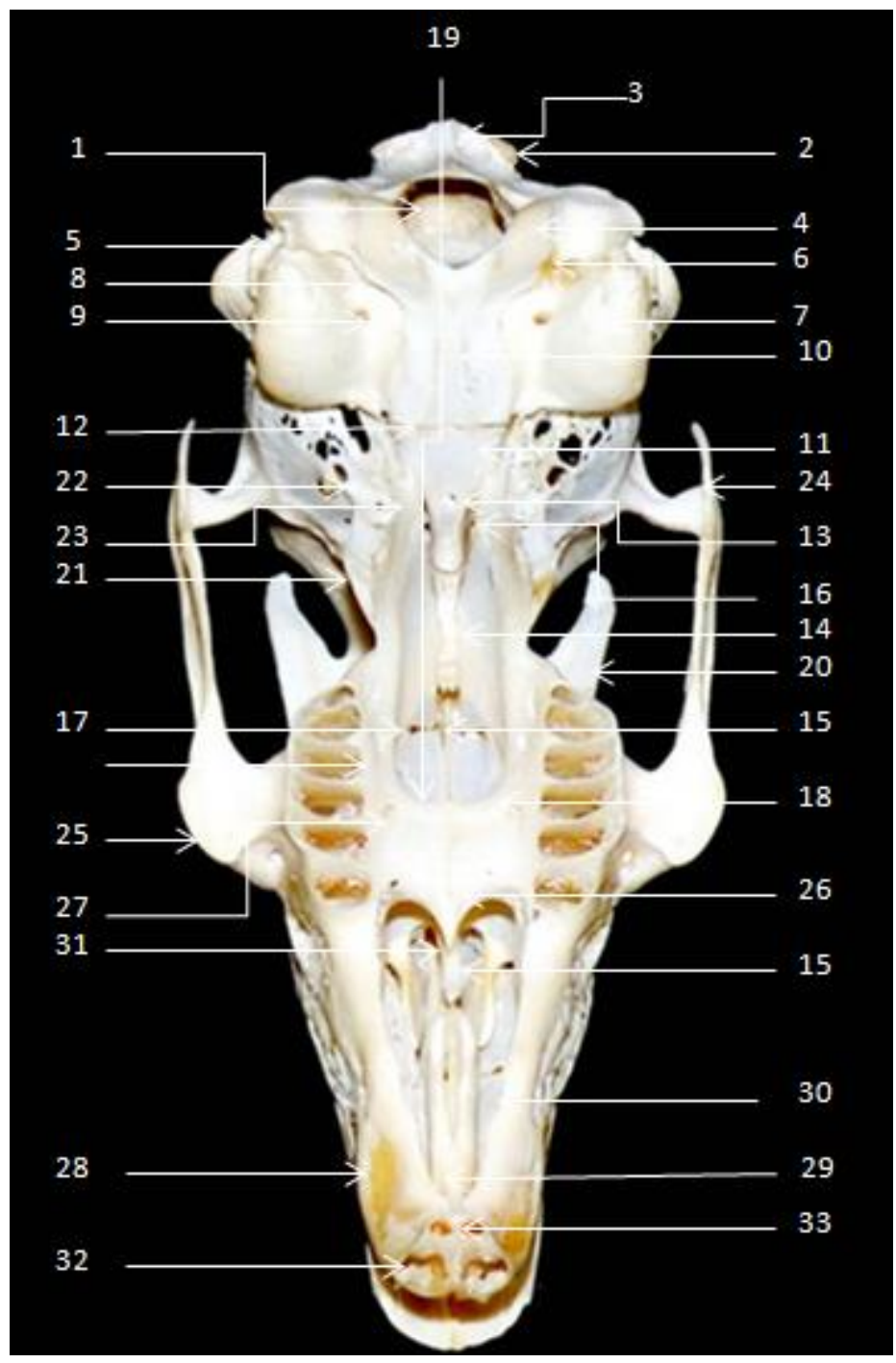

Fig (3): Ventral view of the skull of African Savanna Hare

1 Foramen magnum, 2 Nuchal crest, 3 External occipital protruberance, 4 Occipital condyle, 5 Jugular process, 6 Hypoglossal nerve canal, 7 Tympanic bulla, 8 Jugular foramen, 9 Carotid canal, 10 Basilar part of occipital bone, 11 Basisphenoid bone, 12 Basilar tubercle, 13 Craniopharyngeal canal, 14 Presphenoid bone, 15 Vomer, 16 Orbital fissure, 17 Perpendicular plate of palatine bone, 18 Horizontal plate of palatine bone, 19 Choana, 20 Supraorbital margin, 21 Pterygoid fossa, 22 Alapresphenoid, 23 Pterygoid process, 24 Zygomatic bone, 25 Facial tuber, 26 Palatine process of maxilla bone, 27 Major palatine foramen, 28 Body of incisive bone, 29 Palatine process of 28,30 Ventral nasal concha, 31 Palatine fissure, 32 Dental part of 28, 33 Alveolar process of 28. 


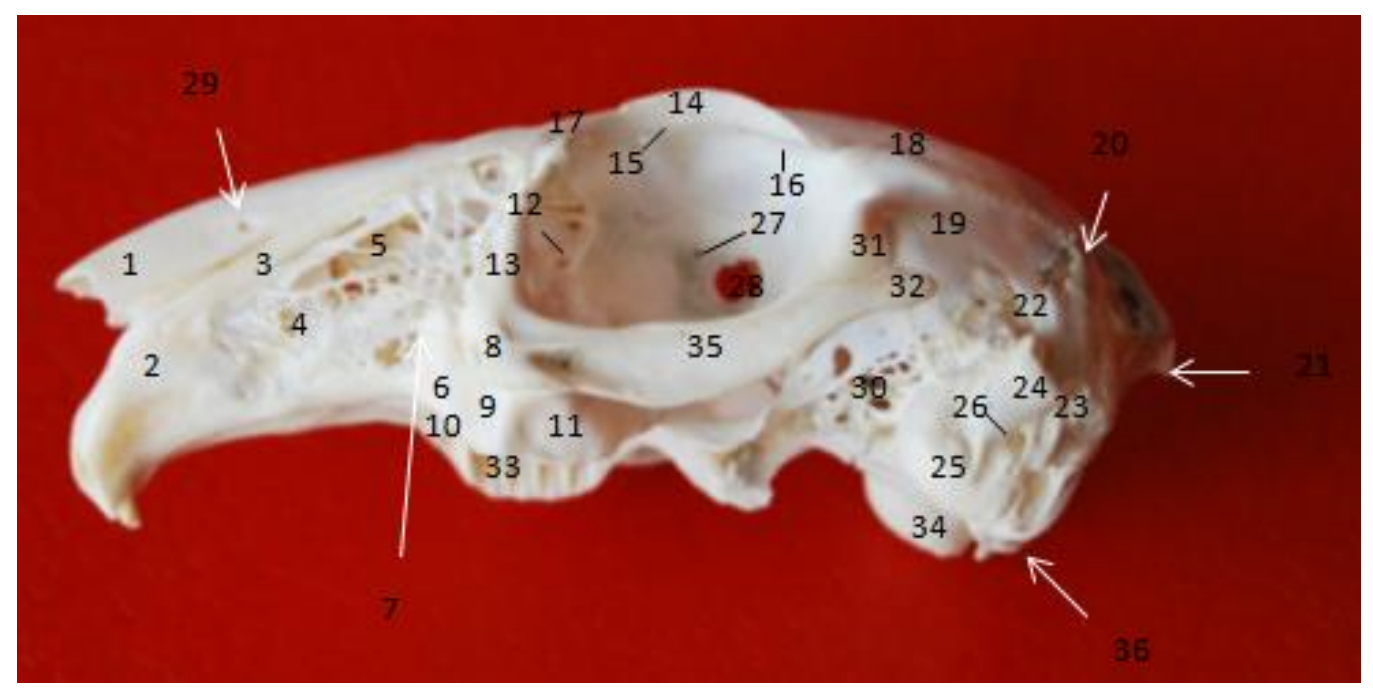

\section{Fig (4): Left lateral view of the skull of African Savanna Hare}

1 Nasal bone , 2 Body of incisive bone, 3 Nasal process of incisive, 4 Body of maxilla, 5 Perforated Facial surface of 4, 6 Facial tuber, 7 Infraorbital foramen, 8 Maxilla tuber, 9 Zygomatic process of 4, 10 Alveolar process of 4, 11 Zygomatic bone, 12 Lacrimal foramen, 13 Nasolacrimal bone, 14 Supraorbital margin, 15 Rostral supraorbital incisure, 16 Caudal supraorbital incisure, 17 Nasal margin of frontal bone, 18 Parietal bone, 19 Temporal bone, 20 Interparietal bone, 21 Nuchal crest, 22 Retrotympanic process, 23 Mastoid process, 24 External acoustic meatus, 25 Tympanic bulla, 26 Stylomastoid foramen, 27 Ethmoidal foramen, 28 Optical canal, 29 Nasal foramen of 1, 30 Mastoid part of 19, 31 Zygomatic process of 19, 32 Projected portion of temporal process of 11, 33 Alveolar process of 4, 34 Occipital condyle, 35 Zygomatich arch, 36 Jugular process 


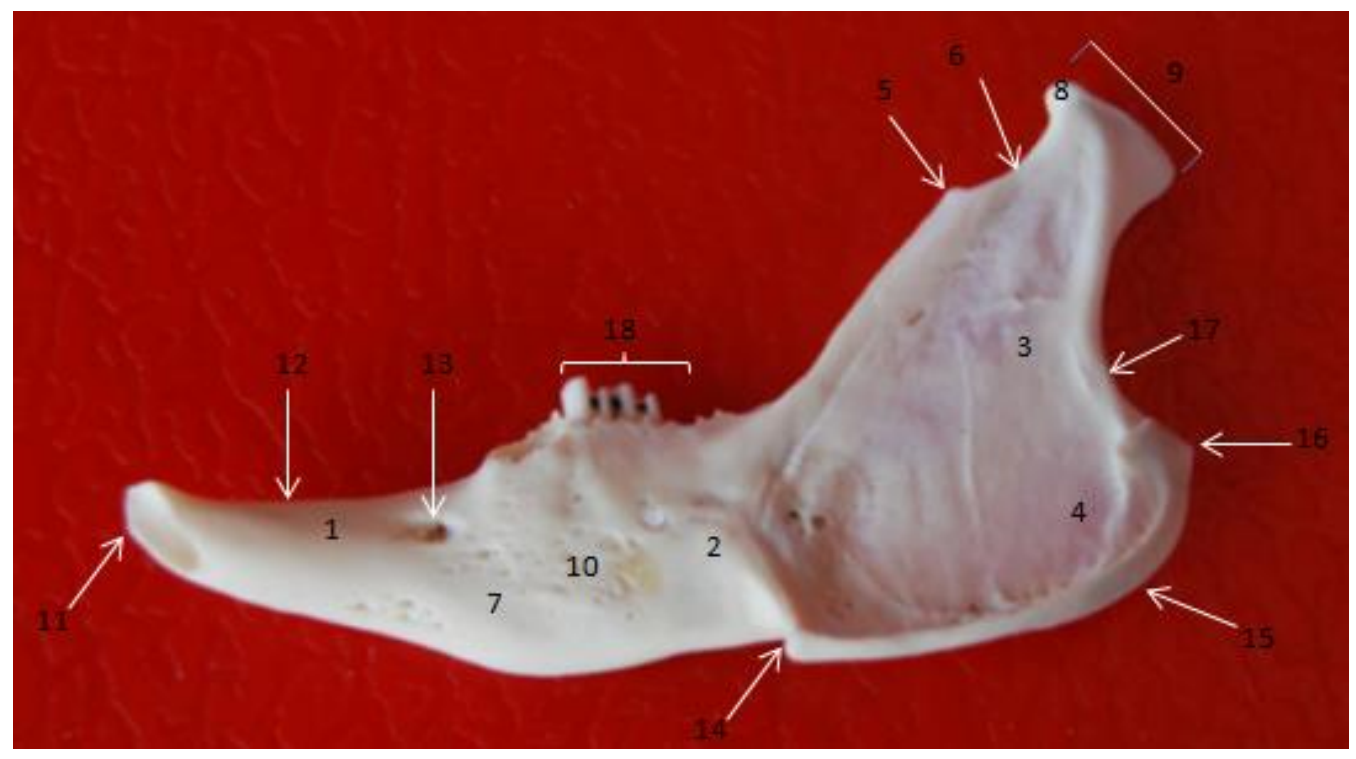

Fig (5): Lateral view of the left half of the mandible of Africana Savanna hare

1 Body of mandible- incisive part, 2 Body of mandible- molar part, 3 Mandibular ramus, 4 Masseter fossa, 5 Coronoid process, 6 Mandibular notch, 7 Labial surface, 8 Head of condyloid process, 9 Condyloid process, 10 Numerous foramina, 11 Mandibular incisure, 12 Interalveolar margin, 13 Mental foramen, 14 Vasorumincisure, 15 Angle of mandible, 16 Angular process, 17 Mandibular collum, 18 Premolar and molar teeth 

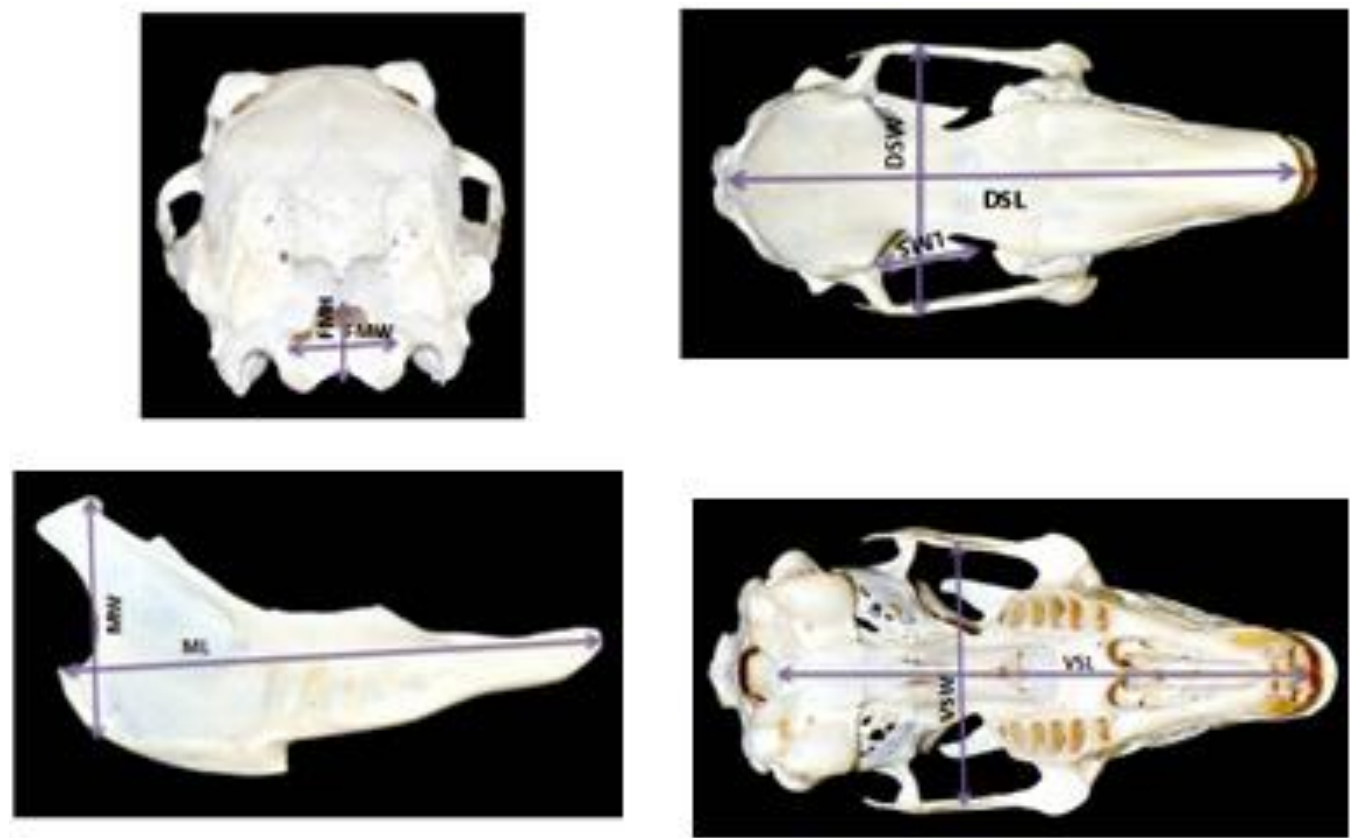

Fig (6): Some of the morphometric parameters of Africana Savanna hare. MLMandibular length, MH- Mandibular height, DSL- Dorsal skull length, VSL- Ventral skull length, DSW- Dorsal skull width, VSW-Ventral skull width, LMS-Length of margo supraorbital, FMH-Foramen magnum height, FMW-Foramen magnum width. 


\section{Animal species in this Issue}

\section{African savanna hare (Lepus microtis)}

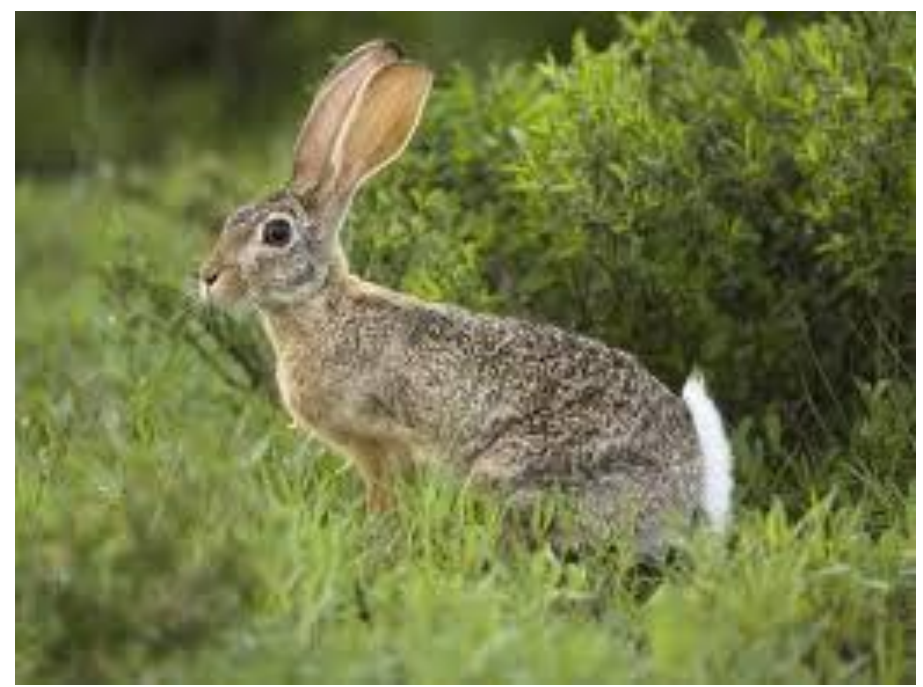

Kingdom: Animalia \& Phylum: Chordata \& Class: Mammalia \& Order: Lagomorpha \& Family: Leporidae \& Genus: Lepus \& Species: L. microtis

The African savanna hare (Lepus microtis) is a species of mammal in the family Leporidae, native to Africa. It is native to diverse regions and habitats of Africa, including savannas and the Sahel. It is found in: Algeria, Botswana, Burundi, Chad, the Democratic Republic of the Congo, Ethiopia, the Gambia, Guinea, Guinea-Bissau, Kenya, Libya, Mali, Mauritania, Morocco, Mozambique, Namibia, Niger, Rwanda, Senegal, Sierra Leone, South Africa, Sudan, Tanzania, Tunisia, Uganda, and Zambia. The IUCN has listed its conservation status as being of "least concern".

The African savanna hare is a medium-sized species growing to a length of 41 to $58 \mathrm{~cm}$ with a weight of 1.5 to 3 kilograms. The ears have black tips, the dorsal surface of head and body is greyish-brown, the flanks and limbs are reddishbrown and the under parts are white. The general colouring is richer in tone than other hares, especially in mountain regions where the hares are a rather darker shade. The tail is black above and white below. This hare looks very similar to the Cape hare in appearance but can be told apart by its distinctively grooved incisors.

Source: Wikipedia, the free encyclopaedia 